\title{
IGH Switch Breakpoints in Burkitt Lymphoma: Exclusive Involvement of Noncanonical Class Switch Recombination
}

\author{
Jeroen E. J. Guikema, ${ }^{\prime \dagger}$ Conny de Boer, ${ }^{\prime}$ Eugenia Haralambieva, ${ }^{\prime}$ Laura A. Smit, ${ }^{2}$ Carel J. M. van Noesel, ${ }^{2}$ \\ Ed Schuuring,' and Philip M. Kluin ${ }^{1 *}$ \\ 'Department of Pathology and Laboratory Medicine, University Medical Center Groningen, Groningen, The Netherlands \\ ${ }^{2}$ Department of Pathology, Academic Medical Center, Meibergdreef 9, II05 AZ Amsterdam, The Netherlands
}

Most chromosomal $\mathrm{t}(8 ; \mid 4)$ translocations in sporadic Burkitt lymphomas $(\mathrm{BL})$ are mediated by immunoglobulin class switch recombination (CSR), yet all tumors express IgM, suggesting an incomplete or exclusively monoallelic CSR event. We studied the exact configuration of both the nontranslocated IGH allele and the MYC/IGH breakpoint by applying a combination of lowand high-resolution methods (interphase FISH, DNA fiber FISH, long-distance PCR, and Southern blotting) on I6 BL. IGH class switch events involving the nontranslocated IGH allele were not observed. Thirteen cases had MYC/IGH breakpoints in or nearby IGH switch (S) sites, including five at $\mathrm{S} \mu$, three at $\mathrm{S} \gamma$ and five at $\mathrm{S} \alpha$. All eight translocations with a breakpoint at $\mathrm{S} \gamma$ or $\mathrm{S} \alpha$ were perfectly reciprocal, without deletion of $\mathrm{C} \mu-\mathrm{C} \delta$ or other $\mathrm{CH}$ elements. Internal $\mathrm{S} \mu$ deletions claimed to be a marker for CSR activity and implicated in stabilization of IgM expression were found in BL but did not correlate with downstream translocation events. This study shows that switch breakpoints in sporadic BL are exclusively resolved by a noncanonical recombination mechanism involving only one switch region. (1) 2006 Wiley-Liss, Inc.

\section{INTRODUCTION}

Burkitt lymphoma (BL) is characterized by a specific chromosomal translocation involving the $M Y C$ locus located on 8q24 and one of the three immunoglobulin ( $\mathrm{Ig})$ loci $(I G H, I G K, I G L)$, resulting in the juxtaposition of the $M Y C$ gene to the immunoglobulin enhancers. Several studies reported the mapping of the $M Y C$ and $I G H$ breakpoints involved in the $t(8 ; 14)$, association of breakpoints with the geographical origin of the patient, and MYC expression levels (Pelicci et al., 1986; Neri et al., 1988; Gutierrez et al., 1992; Wilda et al., 2004). In general, the exact position of the $I G H$ breakpoints provides important information on the origin of the translocation, since the breakpoints likely are mediated by mechanisms that are also active during the physiological $I G$ gene recombinations/mutations, i.e., V-D-J rearrangement, Ig somatic hypermutation (SHM), and $I G H$ class switch recombination (CSR) (for review, see Küppers and DallaFavera, 2001; some experimental evidence for the role of SHM in translocations can be found in Bemark and Neuberger, 2003).

In BL, breakpoints in $I G H$ are located either in the VDJ-region, the switch $\mu$ region $(\mathrm{S} \mu)$ or in the downstream switch regions ( $\mathrm{S} \gamma$ or $\mathrm{S} \alpha$ ). Breakpoints in the VDJ-region are postulated to be generated by the SHM process in early germinal center B cells. Breakpoints in the switch regions are most probably initiated by an erroneous CSR process. In a previous long distance PCR study on 25 sporadic type pediatric BLs, all breakpoints in the constant gene region were at switch sites: 12 at $\mathrm{S} \alpha, 7$ at $\mathrm{S} \gamma$, and 6 at $S \mu$ (Wilda et al., 2004). However, these PCR-based studies have a limited resolution and do not allow the assessment of the configuration of the entire $I G H$ locus.

Other important characteristics of germinal center derived lymphomas are (ongoing) SHM, CSRrelated events like internal $S \mu$ deletions $(\Delta S \mu)$ and downstream class switch recombinations, as recently described by us and others (Zhang et al., 1995; Vaandrager et al., 1998; Nardini et al., 2000; Dudley et al., 2002). In IgM-expressing follicular lymphomas downstream CSR events were associated with $\Delta \mathrm{S} \mu$, suggesting that the internal deletion

Supported by: Dutch Cancer Foundation; Grant number: RUG2000-2207.

*Correspondence to: Philip M. Kluin, Department of Pathology and Laboratory Medicine, University Medical Center Groningen, Hanzeplein 1, P.O. Box 30.001, 9700 RB, Groningen, The Netherlands. E-mail: p.m.kluin@path.umcg.nl

${ }^{\dagger}$ Present address: Department of Molecular Genetics and Microbiology, Program in Immunology and Virology, University of Massachusetts Medical School, 55 Lake Ave North, Worcester, MA 01655 , USA.

Received 22 November 2005; Accepted 2 May 2006

DOI 10.1002/gcc.20345

Published online 30 May 2006 in

Wiley InterScience (www.interscience.wiley.com). 
TABLE I. Summary of Interphase FISH, Southern Blotting, and LD-PCR Results

\begin{tabular}{|c|c|c|c|c|c|c|c|c|}
\hline $\begin{array}{l}\text { Patients \& } \\
\text { cell lines }\end{array}$ & Origin & $\begin{array}{c}\text { Sex \& } \\
\text { age (yrs) }\end{array}$ & Localization & $\begin{array}{c}\text { Interphase } \\
\text { FISH }\end{array}$ & $\begin{array}{c}\text { Southern } \\
\text { blotting } \\
\text { switch regions }\end{array}$ & $\mathrm{S} \mu \mathrm{LD}-\mathrm{PCR}$ & IGHIMYC LD-PCR & Conclusion \\
\hline $94-738$ & sporadic & F 8 & abdomen & $\mathrm{JH} / \mathrm{S} \mu$ & $\mathrm{R} \mathrm{S} \mu$ & G & MYC/C $\mu 6.5 \mathrm{~kb}$ & S $\mu$ breakpoint \\
\hline $98-5735$ & sporadic & M7 & abdomen & $\mathrm{JH} / \mathrm{S} \mu$ & $\mathrm{R} \mathrm{S} \mu ; \Delta \mathrm{S} \mu$ & $\Delta \mathrm{l} .9 \mathrm{~kb}$ & N.A. & S $\mu$ breakpoint \\
\hline $99-375$ & sporadic & M6 & abdomen & $\mathrm{JH} / \mathrm{S} \mu$ & $\mathrm{R} \mathrm{S} \mu$ & G & N.A. & $\mathrm{S} \mu$ breakpoint \\
\hline $94-5883$ & sporadic & M4 & abdomen & $\mathrm{JH} / \mathrm{S} \mu$ & $\mathrm{R} \mathrm{S} \mu$ & G & $M Y C / C \mu 5.8$ kb & $\mathrm{S} \mu$ breakpoint \\
\hline $01-7243$ & sporadic & M5 & urinary bladder & $\mathrm{S} \gamma / \mathrm{S} \alpha$ & $\mathrm{R} \mathrm{S} \gamma ; \Delta \mathrm{S} \mu$ & $\Delta 3.0 \mathrm{~kb}$ & $\mathrm{MYC} / \mathrm{C} \gamma 4.8 \mathrm{~kb}$ & Sy breakpoint \\
\hline $02-5814$ & sporadic & MI2 & urinary bladder & $\mathrm{S} \gamma / \mathrm{S} \alpha$ & $\mathrm{R} \mathrm{S} \gamma ; \Delta \mathrm{S} \mu \Delta \mathrm{S} \mu$ & $\Delta 2.8+3.0 \mathrm{~kb}$ & $M Y C / C \gamma 7.0 \mathrm{~kb}$ & Sy breakpoint \\
\hline $98-3815$ & sporadic & MI3 & abdomen & $\mathrm{S} \gamma / \mathrm{S} \alpha$ & $\mathrm{R} \mathrm{S} \alpha ; \Delta \mathrm{S} \mu \Delta \mathrm{S} \mu$ & $\Delta \mathrm{l} .8 \mathrm{~kb}$ & N.A. & S $\alpha$ breakpoin \\
\hline $98-4847$ & sporadic & $M 12$ & abdomen & $\mathrm{S} \gamma / \mathrm{S} \alpha$ & $\mathrm{R} \mathrm{S} \alpha ; \Delta \mathrm{S} \gamma 2-\mathrm{S} \gamma 4$ & G & N.A. & S $\alpha$ breakpoin \\
\hline $98-15878$ & sporadic & M9 & ileocecum & $\mathrm{S} \gamma / \mathrm{S} \alpha$ & $\mathrm{R} \mathrm{S} \alpha$ & G & N.A. & $\mathrm{S} \alpha$ breakpoin \\
\hline $96-13428$ & sporadic & M6 & abdomen & $\mathrm{S} \gamma / \mathrm{S} \alpha$ & $\mathrm{R} \mathrm{S} \alpha$ & G & N.A. & S $\alpha$ breakpoin \\
\hline $94-9283$ & sporadic & M I7 & abdomen & $\mathrm{JH} / \mathrm{S} \mu$ & $\Delta \mathrm{S} \mu$ & $\Delta 0.2 \mathrm{~kb}$ & N.A. & JH breakpoint \\
\hline $99-12033$ & sporadic & M9 & neck & $\mathrm{JH} / \mathrm{S} \mu$ & G & G & N.A. & $\mathrm{JH}$ breakpoint \\
\hline Jiyoye & endemic & - & - & $\mathrm{JH} / \mathrm{S} \mu$ & $\mathrm{G} ; \Delta \mathrm{S} \mu$ & $\Delta 0.8 \mathrm{~kb}$ & N.A. & JH breakpoint \\
\hline BL-65 & endemic & - & - & $\mathrm{JH} / \mathrm{S} \mu$ & $\mathrm{R} \mathrm{S \mu}$ & G & N.A. & S $\mu$ breakpoint \\
\hline Raji & endemic & - & - & $\mathrm{S} \gamma / \mathrm{S} \alpha$ & N.D. & $\Delta 3.0 \mathrm{~kb}$ & $\mathrm{MYC} / \mathrm{C} \gamma 7.6 \mathrm{~kb}$ & Sy breakpoin \\
\hline CA-46 & sporadic & - & - & $\mathrm{S} \gamma / \mathrm{S} \alpha$ & N.D. & G & $\mathrm{MYC} / \mathrm{C} \alpha 4.2 \mathrm{~kb}$ & S $\alpha$ breakpoin \\
\hline
\end{tabular}

R: illegitimate rearrangement; G: germline configuration; $\Delta$ : internal deletion; N.D.: Not determined; N.A.: Not assessable.

renders $\mathrm{S} \mu$ unavailable for CSR, thereby favoring downstream recombinations (Vaandrager et al., 1998).

Chromosomal breakpoints in the $I G H$ switch regions are solely found in tumors arising from (post-) germinal center B cells. For instance, the majority of multiple myelomas have such translocations (Bergsagel and Kuehl, 2001; Kuehl and Bergsagel, 2002). Several recurrent partner chromosomes may be involved in these breakpoints. DNA sequence analysis of the breakpoints and flanking regions reveal that, in many instances, the breakpoints are located in $S \gamma$ or $S \alpha$. The breakpoints on the derivative chromosomes in these cases involved the $S \mu$ region or the $5^{\prime}$-end of $S \gamma$ or $\mathrm{S} \alpha$, implicating that these breakpoints are mediated by a canonical CSR, accompanied by deletion of the $S \mu-S \gamma$ or $S \mu-S \alpha$ regions, or a noncanonical CSR without deletion of $I G H$ constant regions.

Although independently reported (Showe et al., 1985; Chesi et al., 1997; McKeithan et al., 1997; Gilles et al., 2000; Schmidt et al., 2004; Guikema et al., 2005), it is unknown whether chromosomal translocations with breakpoints in downstream $I G H$ switch regions but not in $S \mu$ are regularly encountered in certain lymphomas.

In this report, we present a comprehensive analysis of the $I G H$ alleles in BL and consistently show that the switch breakpoints are perfectly reciprocal, without deletion of intervening DNA between $S \mu$ and any of the downstream switch regions. These data suggest that switch breakpoints in BL are exclusively mediated by a noncanonical CSR involving only one switch region.

\section{MATERIALS AND METHODS}

\section{Patient Material}

Frozen tissue samples from 12 sporadic Burkitt lymphoma (BL) patients were retrieved from the tissue banks of the Department of Pathology of the University Medical Center Groningen and the Department of Pathology of the Academic Medical Center, Amsterdam. All BL cases were diagnosed using standard histology and immunohistochemistry for IgM, CD10, Ki67, and a FISH segregation assay for $M Y C$ as previously described (Haralambieva et al., 2004). BL cases were reviewed by two pathologists (E.H. and P.K.). Frozen sections used for FISH and DNA isolation contained at least $80 \%$ tumor cells in all studied cases. FISH and immunohistochemistry data from the BL cases from the University Medical Center Groningen has been published elsewhere (Haralambieva et al., 2004). Patient characteristics are listed in Table 1. This study was approved by the ethical committee of the University Medical Center Groningen.

\section{BL Cell Lines}

The endemic BL cell lines Jiyoye and Raji were obtained from the American Type Culture Collection (Manassas, VA); the sporadic BL cell line CA46 was obtained from the Deutsche Sammlung von Mikroorganismen und Zellkulturen GmbH (Braunschweig, Germany); the endemic BL-65 cell line was a kind gift from Dr. Lenoir (IARC, Lyon, France) (Lenoir et al., 1985). All cell lines were maintained in supplemented RPMI 1640 (Cambrex Bio 


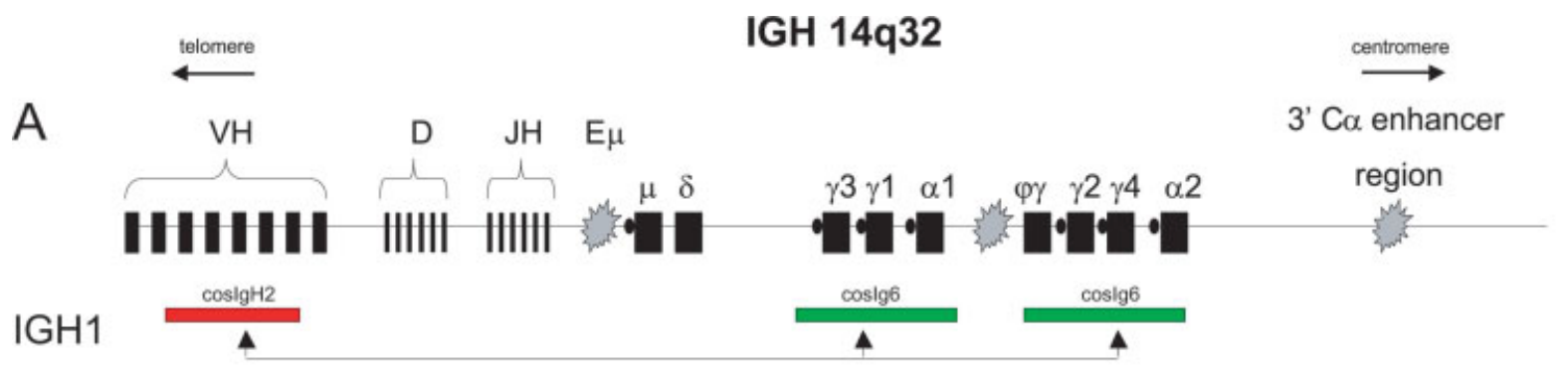

IGH2

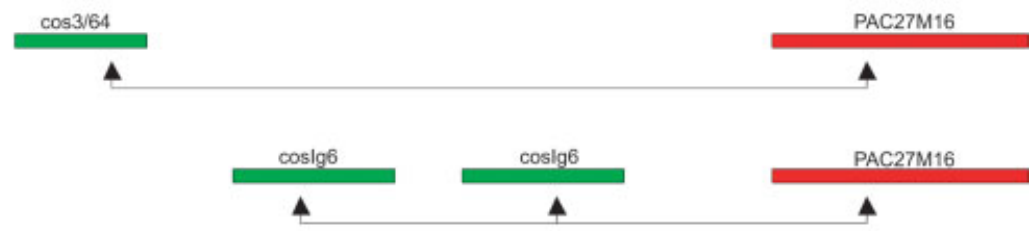

B

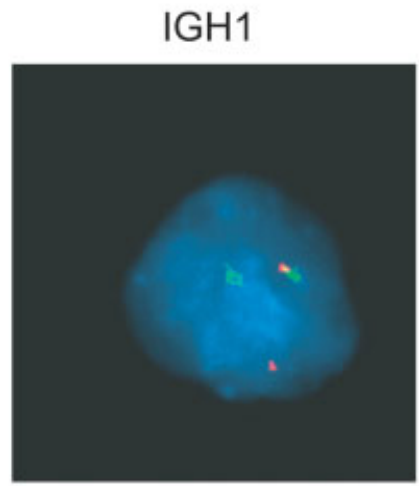

C

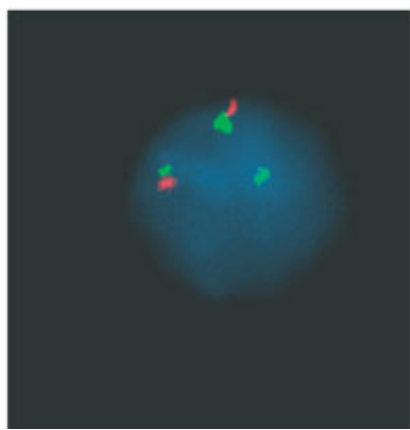

Figure I. Interphase FISH segregation assay for IGH/I4q32. A: Schematic overview of the IGH locus and interphase FISH probes used for detection of $I G H / I 4 q 32$ breakpoints. B: BL tumor with an IGH breakpoint located in the $\mathrm{JH} / \mathrm{S} \mu$ region showing a segregation pattern using probe set IGHI (coslgH2 and coslg6) and colocalization patterns using probe sets IGH2 (cos3/64 and PAC27MI6) and IGH3 (coslg6 and

Science, Walkersville, Maryland) with $10 \%$ FCS (Cambrex).

\section{Interphase and DNA Fiber FISH}

An interphase FISH segregation analysis was set up to determine the relative location of break-
IGH2
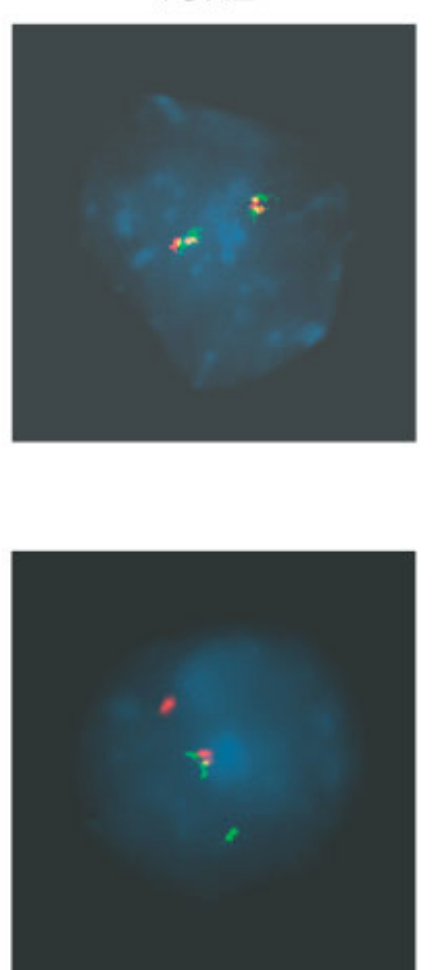

IGH3
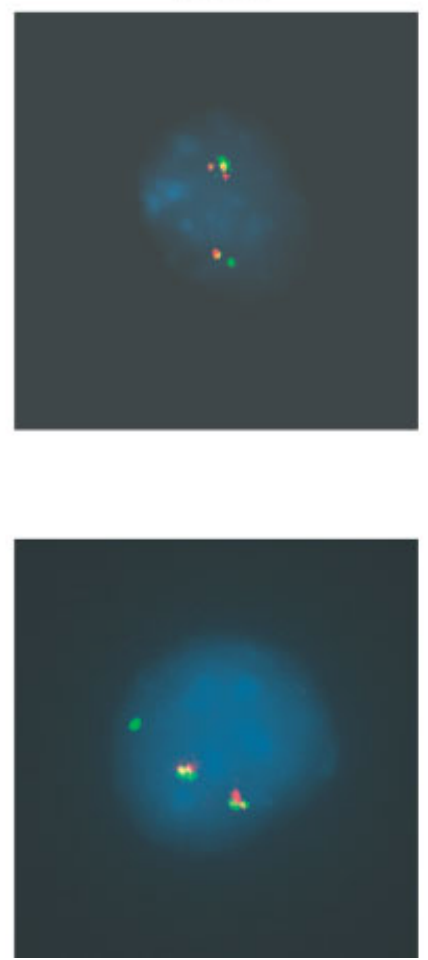

PAC27M 16). C: BL tumor with a breakpoint in a S $\gamma$ or $\mathrm{S} \alpha$ region, showing a segregation pattern with probe set IGH2 and a colocalization pattern with an extra coslg6 signal using probe sets IGHI and IGH3. [Color figure can be viewed in the online issue, which is available at www.interscience.wiley.com.]

points within the $I G H$ locus on $14 \mathrm{q} 32$. Using three different probe combinations, spanning the entire $I G H$ locus $5^{\prime}$ from the $\mathrm{VH}$-genes through the $3^{\prime} \mathrm{C} \alpha$ enhancer region (Fig. 1A), breakpoints were detected in all patient samples and cell lines. Probes for $I G H$ and $M Y C$ used in this study were partly 
TABLE 2. Primer Sequences

\begin{tabular}{|c|c|c|c|}
\hline Primer & Sequence $5^{\prime}$ to $3^{\prime}$ & Target & Reference \\
\hline $\mathrm{JH}$ & ACCTGAGGAGACGGTGACCAGGGT & IGH/MYC & Basso et al. (1999) \\
\hline $\mathrm{C} \alpha / 0 \mathrm{I}$ & TCGTGTAGTGCTTCACGTGGCATGTCACGGACTTG & IGH/MYC & Basso et al. (1999) \\
\hline $\mathrm{C}_{\gamma} / 02$ & AGGGCACGGTCACCACGCTGCTGAGGGAGTAGAGT & IGH/MYC & Basso et al. (I999) \\
\hline $\mathrm{C} \mu / 03$ & TGCTGCTGATGTCAGAGTTGTTCTTGTATTTCCAG & IGH/MYC & Basso et al. (I 999) \\
\hline MYC/04 & ACAGTCCTGGATGATGATGTTTTTGATGAAGGTCT & IGH/MYC & Basso et al. (1999) \\
\hline $5 \mathrm{MI}$ & AGCCCTTGTTAATGGACTTGGAGG & $\mathrm{S} \mu$ & Fenton et al. (2003) \\
\hline $3 M$ & CGTTCTGAGTGCCCTCACTACTTGC & $\mathrm{S} \mu$ & Fenton et al. (2003) \\
\hline $5^{\prime} \sigma \mu$ & CAGATCTGAAAGTGCTCTACTG & $\mathrm{S} \mu$ & Nardini et al. (2002) \\
\hline $3 M R B$ & GTGATGGGAACGCAGTGTAGA & $\mathrm{S} \mu$ & Nardini et al. (2002) \\
\hline $5 M F B$ & GGCAATGAGATGGCTTTAGCTGA & $\mathrm{S} \mu$ & Nardini et al. (2002) \\
\hline $\mathrm{CmRI}$ & ACACGTGTCAGCCCGGTGCC & $\mathrm{S} \mu$ & Nardini et al. (2002) \\
\hline
\end{tabular}

described elsewhere (Vaandrager et al., 1998; Haralambieva et al., 2004). In addition, the PAC27M16 (kind gift from Dr. D. Cox, Hospital for Sick Children, Toronto, Canada) mapping to the most $3^{\prime}$ located $I G H \mathrm{C} \alpha$ enhancer region and the cosmid IgH2 (kind gift from Dr. T. Rabbitts, MRC Laboratory of Molecular Biology, Cambridge, United Kingdom) mapping to the telomeric part of the $I G H$ locus encompassing the distal VH genes were used for interphase FISH and/or DNA fiber FISH analysis.

Preparation of interphase nuclei and DNA fibers was performed as described previously (Vaandrager et al., 1998). For dual color FISH, probes were labeled with digoxigenin-11-dUTP (Roche, Basel, Switzerland) or biotin-16-dUTP (Invitrogen, Carlsbad, California) by standard nick-translation. The hybridization solution contained $50 \%$ formamide (for interphase FISH) or $30 \%$ formamide (for DNA fibers), $10 \%$ dextran sulfate, $50 \mathrm{mM}$ sodium phosphate, $\mathrm{pH}=7,2 \times \mathrm{SSC}, 3 \mathrm{ng} / \mu \mathrm{l}$ of each probe, and a 50-fold excess of human C0t-1 DNA (Invitrogen). Immunodetection was performed as described earlier (Haralambieva et al., 2004). Images were captured using a Leica DMRA2 fluorescence microscope (Leica Microsystems, Wetzlar, Germany) equipped with a Leica DC 350F charge-coupled device camera. Digital images were processed with Leica CW4000 and Adobe Photoshop software, version 7.0.

\section{Southern Blotting}

High molecular weight genomic DNA was extracted from frozen tissue sections $(3 \times 45 \mu \mathrm{m})$ by the 'salting out' procedure. Approximately $5 \mu \mathrm{g}$ of genomic DNA was digested with HindIII or SphI (all purchased from Invitrogen). Digested DNA was run overnight on $0.7 \%, \times 0.5$ Tris-Boric acidEDTA (TBE) agarose gels. Subsequently, DNA was transferred to positively charged nylon mem- branes (Roche) by capillary blotting in $\times 20$ Standard Saline Citrate (SSC). Digoxigenin-labeled probes, which flank the immunoglobulin switch regions both $5^{\prime}$ and $3^{\prime}$, were generated by PCR using the primers described previously (Chesi et al., 1996). Alkali-labile digoxigenin-11-dUTP (Roche) was added to each PCR reaction at a final concentration of $7 \mu \mathrm{M}$. Labeled probes were purified by PCRclean-up (Qiagen, Hilden, Germany). Hybridizations were performed in the Dig-Easy $\mathrm{Hyb}^{\mathrm{TM}}$ hybridization mixture (Roche) at $42^{\circ} \mathrm{C}$. Stringency washes were performed with $2 \times \mathrm{SSC}, 0.1 \%$ sodium dodecyl sulfate (SDS) twice at room temperature, followed by $0.1 \times \mathrm{SSC}, 0.1 \%$ SDS twice at $68^{\circ} \mathrm{C}$. Membranes were developed by alkaline phosphatase conjugated rabbit-anti-dig $\mathrm{F}\left(\mathrm{ab}^{\prime}\right)$ fragments and the chemoluminescent substrate CDP-Star ${ }^{\text {TM }}$ (Roche). Kodak XAR films (Eastman Kodak, Rochester, New York) were exposed for a maximum of $2 \mathrm{hr}$ to developed membranes. Membranes were stripped in $0.2 \mathrm{M} \mathrm{NaOH}, 0.1 \% \mathrm{SDS}$ for $15 \mathrm{~min}$ at $37^{\circ} \mathrm{C}$.

\section{Long-Distance PCR}

Breakpoints within $M Y C$ and $I G H$ were determined by long-distance polymerase chain reaction (LD-PCR) using the Elongase ${ }^{\mathrm{TM}}$ PCR system (Invitrogen). Primers were described previously (Basso et al., 1999). Integrity of $\mathrm{S} \mu$ was assessed by LD-PCR using three overlapping primer sets, which span from the intronic enhancer $(E \mu)$ to the coding region of $\mathrm{C} \mu$. The $\mathrm{S} \mu$ region was amplified using the 5M1-3M primer set (Fenton et al., 2003), whenever this yielded a band of the expected size (germline $\mathrm{S} \mu$ ); genomic DNA was subsequently subjected to LD-PCR with the $5^{\prime} \sigma \mu-3 \mathrm{MRB}$ primer set, located $5^{\prime}$ from the $5 \mathrm{M} 1-3 \mathrm{M}$ primer set, and the $5 \mathrm{MFB}-\mathrm{CmR} 1$ primer set (Nardini et al., 2002), located $3^{\prime}$ from the $5 \mathrm{M} 1-3 \mathrm{M}$ primer set. Sequences of primers are listed in Table 2. 
GUIKEMA ET AL.

TABLE 3. Southern Blot Analysis of $\mathrm{S} \mu \mathrm{S} \gamma$, and $\mathrm{S} \alpha$ Regions in BL Tumors

\begin{tabular}{|c|c|c|c|c|c|c|c|c|}
\hline \multirow[b]{3}{*}{ BL } & \multicolumn{8}{|c|}{ Rearranged fragments (kb) } \\
\hline & \multicolumn{2}{|c|}{ HindIII } & \multicolumn{2}{|c|}{ Sphl } & \multicolumn{2}{|c|}{ HindIII } & \multicolumn{2}{|c|}{ HindIII } \\
\hline & $5^{\prime} S \mu$ & $3^{\prime} S \mu$ & $5^{\prime} S \mu$ & $3^{\prime} S \mu$ & $5^{\prime} S \gamma$ & $3^{\prime} S \gamma$ & $5^{\prime} \mathrm{S} \alpha$ & $3^{\prime} \mathrm{S} \alpha$ \\
\hline $94-738$ & 3.6 & 20.8 & 5.6 & 11.6 & G & G & G & G \\
\hline $98-5735$ & $\begin{array}{l}9.0 * \\
7.8\end{array}$ & $9.0 *$ & $\begin{array}{l}6.3^{*} \\
6.5\end{array}$ & $6.3^{*}$ & G & G & G & G \\
\hline $99-375$ & 4.2 & G & $\begin{array}{l}5.6 \\
7.1\end{array}$ & G & G & G & G & G \\
\hline $94-5883$ & 5.3 & 24.6 & 6.9 & 15.3 & G & G & G & G \\
\hline $01-7243$ & $8.0^{*}$ & $8.0 *$ & $5.5^{*}$ & $5.5^{*}$ & 5.8 & 4.4 & G & G \\
\hline $02-58 \mid 4$ & $8.1^{*}$ & $8.1^{*}$ & $5.5^{*}$ & $5.5^{*}$ & 3.4 & 2.1 & G & G \\
\hline & $8.3 *$ & $8.3 *$ & $5.7^{*}$ & $5.7^{*}$ & & & & \\
\hline $98-3815$ & $8.8^{*}$ & $8.8^{*}$ & $\begin{array}{l}6.4^{*} \\
7.3^{*}\end{array}$ & $\begin{array}{l}6.4^{*} \\
7.3^{*}\end{array}$ & G & G & 14.8 & 18.8 \\
\hline $98-4847$ & G & G & G & G & $\Delta S \gamma 2-S \gamma 4$ & $\Delta \mathrm{S} \gamma 2-\mathrm{S} \gamma 4$ & 14.3 & 18.8 \\
\hline $98-15878$ & G & G & G & G & G & G & 26.3 & 19.5 \\
\hline $96-13428$ & G & G & G & G & G & G & 15.7 & 19.0 \\
\hline $94-9283$ & G & G & G & G & G & G & G & G \\
\hline $99-12033$ & G & G & G & G & G & G & G & G \\
\hline
\end{tabular}

Genomic DNA was digested with HindIII or Sphl and hybridized with switch region flanking probes $\left(5^{\prime}\right.$ and $\left.3^{\prime}\right)$. Sizes $(\mathrm{kb})$ of the fragments are shown in the table. G: only germline bands detected.

*Internal $S \mu$ deletion; $\Delta$ : deletion.

\section{RESULTS}

\section{Interphase FISH Analysis for IGH and MYC Breakpoints}

In all 16 BLs (12 patient samples and 4 cell lines), $M Y C$ breakpoints could be confirmed by interphase FISH segregation assays using two probe combinations spanning a region of $\sim 1,000 \mathrm{~kb}(700 \mathrm{~kb}$ centromeric till $300 \mathrm{~kb}$ telomeric of $M Y C$ ).

The $I G H$ breakpoints in the $16 \mathrm{BL}$ samples were mapped by interphase FISH, Southern blotting, and LD-PCR (results are summarized in Tables 1 and 3). Using DNA fiber FISH, we could obtain a more comprehensive overview of both the translocated and nontranslocated $I G H$ allele for nine BL tumors (five patient samples and four cell lines). The hybridization patterns representing the translocated as well as the nontranslocated $I G H$ allele were identified for all the studied cases (results summarized in Table 4).

\section{BL Patients and Cell Lines with IGH Breakpoints Located in VDJ or $\mathbf{S \mu}$}

By use of interphase FISH with different probe sets (IGH1, 2 and 3), we determined the breakpoint position in the $I G H$ locus (Fig. 1). Eight BL tumors had a breakpoint in the $\mathrm{VDJ} / \mathrm{S} \mu$ region (Table 1). This was shown by the segregation for probe set IGH1 and a colocalization pattern for the other probe sets (IGH2, IGH3) (Fig. 1B). Using Southern blotting with $S \mu$ flanking probes, in five out of these eight BLs, illegitimate switch recombination fragments were detected, whereas the $S \gamma$ and $S \alpha$-flanking probes showed germline configurations (Table 3, Fig. 2A). In patient samples 9283 and 12033 and in the Jiyoye cell line, the $S \mu$ flanking probes only detected germline bands, which in conjunction with the $I G H$ interphase FISH results, suggest a breakpoint in or nearby VDJ but not in $\mathrm{S} \mu$. Long-distance PCR confirmed a breakpoint in S $\mu$ for two patient samples (736 and 5883) (Table 1). Legitimate switch recombinations could not be detected by Southern blotting in any of these eight BLs.

\section{IGH Breakpoints Involving $\mathbf{S} \gamma$ and $\mathbf{S} \alpha$ are Perfectly Reciprocal in BL}

In the remaining eight BLs, the interphase FISH showed a segregation pattern with probe set IGH2, suggesting a breakpoint in $S \gamma$ or $S \alpha$. Most essentially, both interphase and DNA fiber FISH showed that the $\mathrm{C} \mu-\mathrm{C} \delta$ region was preserved on the der(8) chromosome, indicating that no interstitial $\mathrm{S} \mu-\mathrm{S} \gamma / \alpha$ deletion had occurred. To further prove that the $S \mu$ region was not involved in these breakpoints, Southern blotting was performed with switch region flanking probes. No illegitimate $S \mu$ fragments, but only germline fragments or internal deletions (see later results section) were found in these tumors (Tables 1 and 3, Figs. 2B and 2C). DNA fiber FISH analysis was successful for seven of these BLs and consistently showed that the non- 
TABLE 4. DNA Fiber FISH Results

\begin{tabular}{|c|c|c|c|c|}
\hline $\begin{array}{l}\text { Patients and } \\
\text { cell lines }\end{array}$ & $\begin{array}{c}I G H \\
\text { breakpoint* }\end{array}$ & Fiber FISH results $\operatorname{der}(14)$ & $\begin{array}{l}\text { Fiber FISH } \\
\text { results } \operatorname{der}(8)\end{array}$ & Fiber FISH results $14 q 32$ \\
\hline $0 \mathrm{I}-7243$ & S $\gamma$ & $\begin{array}{c}\text { MYC- } \gamma 3-\gamma \mid-\alpha I-\Psi \gamma-\gamma 2- \\
\gamma 4-\varepsilon-\alpha 2-3^{\prime} C \alpha\end{array}$ & $\mathrm{DJH}-\mu-\delta-8 q 24$ & $D-J H-\mu-\delta-\gamma 3-\gamma I-\alpha I-\Psi \gamma-\gamma 2-\gamma 4-\varepsilon-\alpha 2-3^{\prime} C o$ \\
\hline $02-5814$ & Sy & MYC- $\gamma I-\alpha I-\Psi \gamma-\gamma 2-\gamma 4-\varepsilon-\alpha 2-3^{\prime} C \alpha$ & $D-\jmath H-\mu-\delta-\gamma 3-8 q 24$ & $D J H-\mu-\delta-\gamma 3-\gamma|-\alpha|-\Psi \gamma-\gamma 2-\gamma 4-\varepsilon-\alpha 2-3^{\prime} \mathrm{C} \alpha$ \\
\hline $98-3815$ & $\mathrm{~S} \alpha$ & MYC- $\alpha 2-\Psi \gamma-\gamma 2-\gamma 4-\varepsilon-\alpha 2-3^{\prime} \mathrm{C} \alpha$ & $\begin{array}{l}\text { D-jH- } \mu-\delta-\gamma 3-\gamma I-\alpha I- \\
\Psi \gamma-\gamma 2-\gamma 4-\varepsilon-8 q 24\end{array}$ & $\mathrm{DJH}-\mu-\delta-\gamma 3-\gamma|-\alpha|-\Psi \gamma-\gamma 2-\gamma 4-\varepsilon-\alpha 2-3^{\prime} \mathrm{C} \alpha$ \\
\hline $98-4847$ & $\mathrm{~S} \alpha$ & MYC- $\alpha I-3^{\prime} C \alpha$ & $D J H-\mu-\delta-\gamma 3-\gamma \mid-8 q 24$ & $3^{\prime} \mathrm{C} \alpha$ \\
\hline $98-15878$ & $\mathrm{~S} \alpha$ & MYC $-\alpha 2-3^{\prime} C \alpha$ & $\begin{array}{l}D J H-\mu-\delta-\gamma 3-\gamma|-\alpha|- \\
\quad \Psi \gamma-\gamma 2-\gamma 4-\varepsilon-8 q 24\end{array}$ & $\mathrm{DJH}-\mu-\delta-\gamma 3-\gamma|-\alpha|-\Psi \gamma-\gamma 2-\gamma 4-\varepsilon-\alpha 2-3^{\prime} \mathrm{C} \alpha$ \\
\hline Jiyoye & $\mathrm{JH}$ & $\begin{array}{l}\text { MYC- } \mu-\delta-\gamma 3-\gamma|-\alpha|-\Psi \gamma-\gamma 2- \\
\gamma 4-\varepsilon-\alpha 2-3^{\prime} C_{\alpha}\end{array}$ & $?-8 q 24$ & $\mathrm{DJH}-\mu-\delta-\gamma 3-\gamma|-\alpha|-\Psi \gamma-\gamma 2-\gamma 4-\varepsilon-\alpha 2-3^{\prime} \mathrm{C} \alpha$ \\
\hline BL-65 & $\mathrm{S} \mu$ & $\begin{array}{l}\text { MYC- } \mu-\delta-\gamma 3-\gamma I-\alpha I-\Psi \gamma-\gamma 2- \\
\gamma 4-\varepsilon-\alpha 2-3^{\prime} C_{\alpha}\end{array}$ & $J H-8 q 24$ & $\mathrm{DJH}-\mu-\delta-\gamma 3-\gamma|-\alpha|-\Psi \gamma-\gamma 2-\gamma 4-\varepsilon-\alpha 2-3^{\prime} \mathrm{C} \alpha$ \\
\hline Raji & Sy & $\begin{array}{l}\text { MYC- } \gamma 3-\gamma \mid-\alpha I-\Psi \gamma-\gamma 2- \\
\gamma 4-\varepsilon-\alpha 2-3^{\prime} C \alpha\end{array}$ & $D-J H-\mu-\delta-8 q 24$ & $D J H-\mu-\delta-\gamma 3-\gamma|-\alpha|-\Psi \gamma-\gamma 2-\gamma 4-\varepsilon-\alpha 2-3^{\prime} C \alpha$ \\
\hline CA-46 & $\mathrm{S} \alpha$ & MYC- $\alpha I-\Psi \gamma-\gamma 2-\gamma 4-\varepsilon-\alpha 2-3^{\prime} C \alpha$ & $D J H-\mu-\delta-\gamma 3-\gamma \mid-8 q 24$ & $D J H-\mu-\delta-\gamma 3-\gamma|-\alpha|-\Psi \gamma-\gamma 2-\gamma 4-\varepsilon-\alpha 2-3^{\prime} C \alpha$ \\
\hline
\end{tabular}

*IGH Breakpoint position as determined by interphase FISH and Southern blotting. The pattern of constant regions and MYC/8q24 hybridization signals is described. Unrearranged D and JH regions are designated as D-JH and could be identified by an unrearranged U2-2 probe signal. Rearranged D and $\mathrm{JH}$ regions are represented by $\mathrm{DJH}$. When probe signals for the partner chromosome were not found it was represented by a "?".

translocated $I G H$ allele did not undergo any class switch recombination event (Table 4).

In three BLs with $S \gamma$ or $S \alpha$ breakpoints (7243, 5814, and 3815), interphase FISH revealed three hybridization signals for the cosIg6 probe instead of two. Two cosIg6 signals colocalized with either the VH-flanking probe (IGH1) or the $3^{\prime} \mathrm{C} \alpha$ region probe (IGH3) (Fig. 1C). The cosIg6 probe was originally cloned from the $\mathrm{C} \gamma 3$ region but hybridizes at two adjacent positions within the $I G H$ locus (Fig. 1A, and was shown earlier by DNA fiber FISH (Vaandrager et al., 1998), which is due to an evolutionary duplication. A breakpoint within the area covered by this probe, therefore, yields an extra interphase FISH hybridization signal of comparable intensity in most instances. Two other BLs (15878 and 13428) showed a colocalization pattern with the IGH1 probe set and a segregation pattern without the extra cosIg6 signal with the IGH3 probe set. This pattern suggests an $I G H$ breakpoint at the far $3^{\prime}$ end of the region covered by cosIg6, probably in $\mathrm{S} \gamma 4$ or $\mathrm{S} \alpha 2$.

Additional Southern blotting experiments on the BL cases with $S \gamma$ or $S \alpha$ breakpoints showed $S \gamma$ breakpoints in two patient samples (7243 and 5814; Fig. 2B). IGH/MYC LD-PGR confirmed S $\gamma$ breakpoints in these cases and in the Raji cell line (Table 1). Four patient samples were shown to have a $\mathrm{S} \alpha$ breakpoint by Southern blotting (3815, 4847, 15878, and 13428) (Fig. 2C and Table 3). Additionally, the CA-46 cell line was shown to have a $\mathrm{S} \alpha$ breakpoint, using LD-PGR (Table 1). No (il)legitimate recombinations involving any other switch region than the one affected by the translocation was found in any of the cases. These results consistently show that $S \mu$ is not involved in the BL cases with $S \gamma$ or $S \alpha$ breakpoints.

For BL 4847, an abnormal $I G H$ interphase FISH pattern was found in all experiments. In general, only one hybridization signal was observed with the $\mathrm{C} \mu-\mathrm{C} \delta(3 / 64)$, the $\mathrm{VH}$-flanking probe, and the $\mathrm{C} \gamma-\mathrm{C} \alpha$ probe, but the $3^{\prime} \mathrm{C} \alpha$ enhancer probe yielded two signals. This suggested a large monoallelic telomeric deletion at $14 \mathrm{q} 32$. Using the probe set IGH2, the $\mathrm{C} \mu-\mathrm{C} \delta$ probe did not colocalize with the $3^{\prime} \mathrm{C} \alpha$ enhancer probe, indicating that $\mathrm{C} \mu$ was present on the translocated allele. Using the probe set combinations IGH1 and IGH3, no colocalization of the remaining signals was seen (Fig. 3A). Southern blot analysis with the S $\gamma$ flanking probes demonstrated the absence of any $\mathrm{S} \gamma 2$ and $\mathrm{S} \gamma 4$ region, whereas the $S \mu$ flanking probes revealed only the germline fragment (Tables 1 and 3). The DNA fiber FISH hybridization pattern representing the nontranslocated $I G H$ allele indeed showed loss of the telomeric part of chromosome 14. The translocated $I G H$ allele had a breakpoint at $\mathrm{S} \alpha$, and harbored only a $\mathrm{C} \gamma 3-\mathrm{C} \gamma 1-\mathrm{C} \alpha 1$ constant region cluster (Fig. 3B). These results imply that the Cy2-C $\gamma 4$ $\mathrm{C} \alpha 2$ constant gene cluster was absent on the translocated and the nontranslocated IGH allele. Southern blotting experiments showed no evidence for recombinations between downstream switch regions. An Ig constant region polymorphism could possibly explain the configuration in this BL tumor, but unfortunately, this could not be confirmed because 
A

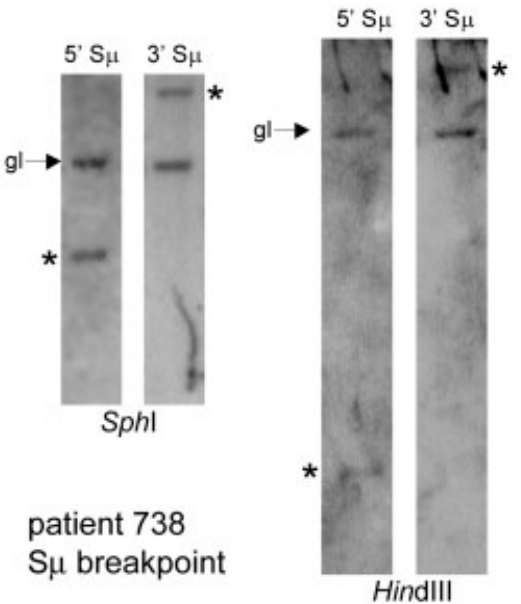

B

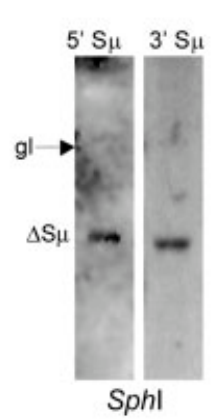

patient 7243

S $\gamma$ breakpoint

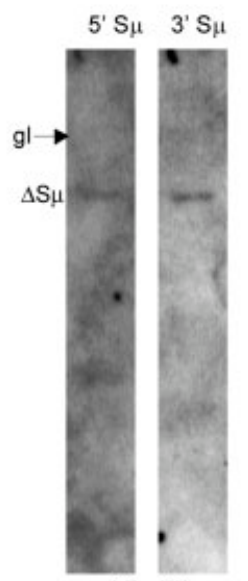

HindIII

C

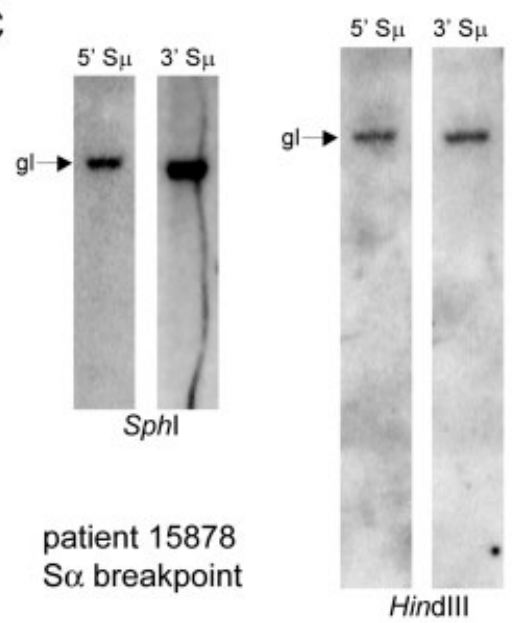

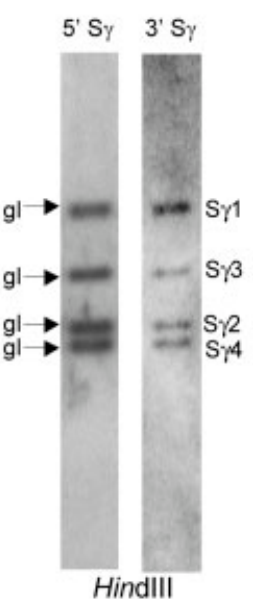

HindIII
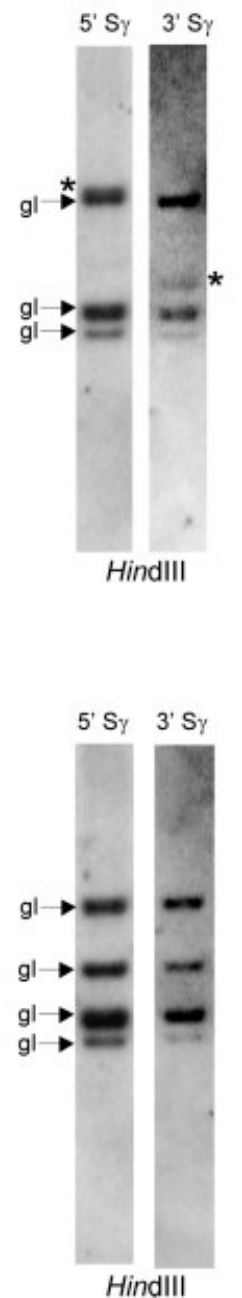

Figure 2. Southern blotting with immunoglobulin switch region flanking probes. A: Patient 738 Southern blotting results, illegitimate $\mathrm{S} \mu$ recombination. B: Patient 7243 Southern blotting results, illegitimate $S \gamma$ recombination and internal S $\mu$ deletion. C: Patient 15878 Southern blotting results, illegitimate $S \alpha$ recombination. HindllI digested genomic DNA fragments were hybridized to $5^{\prime}$ $\mathrm{S} \mu, 3^{\prime} \mathrm{S} \mu, 5^{\prime} \mathrm{S} \gamma, 3^{\prime} \mathrm{S} \gamma, 5^{\prime} \mathrm{S} \alpha$ and $3^{\prime} \mathrm{S} \alpha$ probes. Sphl digested DNA fragments were hybridized to $5^{\prime} S \mu$ and $3^{\prime} S \mu$ probes. The switch regions are in germline configuration when the tumor clone has not undergone isotype switch recombination. Under these circumstances the switch region flanking probes will cohybridize with DNA fragments of the same size. Legitimate (physiological) switch recombination will result in the cohybridization of the $5^{\prime} \mathrm{S} \mu$ probe with the $3^{\prime}$ switch probe of the involved isotype. If any of the $5^{\prime}$ switch region flanking probes hybridizes with a band of a different size than the germline fragment and does not cohybridize with any of the $3^{\prime}$ switch probes the recombination is illegitimate and represents a switch breakpoint. Internal $S \mu$ deletions can be discerned by the cohybridization of both the $5^{\prime} \mathrm{S} \mu$ and the $3^{\prime} \mathrm{S} \mu$ probe with a fragment smaller than the expected germline fragment. gl, germline; $*$, illegitimate recombinations; $\Delta$, deletion. 
A

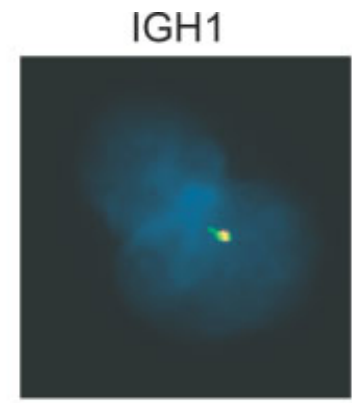

IGH2

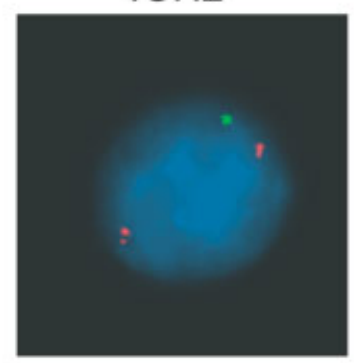

IGH3

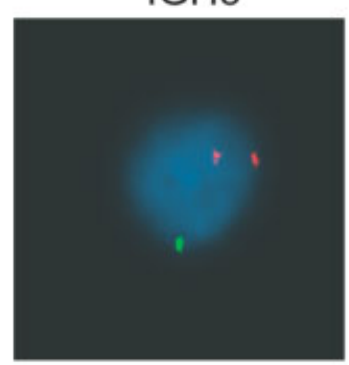

B

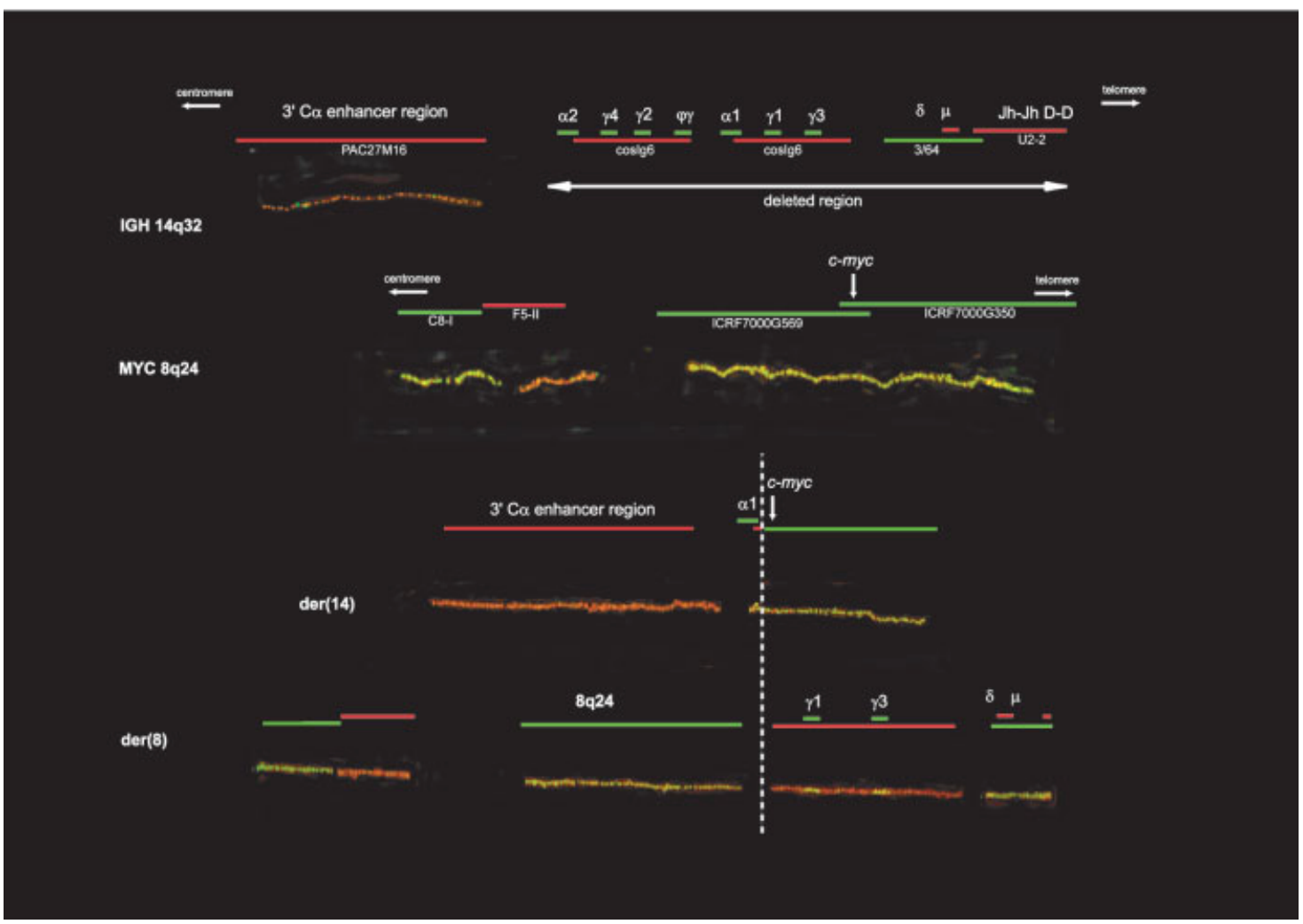

Figure 3. IGH interphase FISH, Southern blotting and DNA fiber FISH results for patient 4847. A: IGH/I4q32 segregation interphase FISH assay showing loss of one IGH allele. Single coslgH2 and coslg6 hybridization signals were observed using probe set IGHI. Probe set IGH2 showed two PAC27MI 6 hybridization signals but only one for $\cos 3 / 64$, which did not colocalize with either PAC27MI 6 signal. Similarly, a loss of one coslg6 signal was observed using probe set IGH3. B: Stretched DNA fibers were hybridized with pooled differentially labeled

normal tissue from this patient was not available. Earlier, we described a polymorphism in a hairy cell leukemia patient, who lacked the Cy2-Cy4C $\alpha 2$ cluster (Vaandrager et al., 1998).

DNA fiber FISH confirmed that the $\mathrm{C} \mu-\mathrm{C} \delta$ probe was juxtaposed to the der(8), also showing a recombined DJH probe signal. Therefore, the part of the $I G H$ locus that is linked to the $\operatorname{der}(8)$ chromosome is responsible for IgM expression in this BL. (red and green) cosmids and PI-derived artificial chromosomes (PACs) covering $\sim 400 \mathrm{~kb}$ of the IGH locus and $200 \mathrm{~kb}$ of MYC at $8 \mathrm{q} 24$. The top half depicts the hybridization patterns of the nontranslocated IGH allele showing a large telomeric deletion, and the nontranslocated MYC allele. The lower half shows the hybridization patterns of the $\operatorname{der}(14)$ and the $\operatorname{der}(8)$ involved in the $t(8 ; \mid 4)$ translocation. [Color figure can be viewed in the online issue, which is available at www.interscience.wiley.com.]

\section{Internal S $\mu$ Deletions Burkitt Lymphomas and Cell Lines}

Large internal $S \mu$ deletions $(\Delta S \mu)$ result from intra switch region recombination and are related to AID expression and class switch recombination (CSR) activity (Dudley et al., 2002). Furthermore, it has been suggested that $\Delta \mathrm{S} \mu$ is involved in IgM isotype stabilization by rendering $S \mu$ unavailable for further CSR (Zhang et al., 1995). Previously, we 
showed that downstream CSR events in IgMexpressing $\mathrm{FL}$ correlated with $\Delta \mathrm{S} \mu$ (Vaandrager et al., 1998). We, therefore, assessed $\Delta S \mu$ in BL by Southern blotting and LD-PCR. Restriction enzyme digested DNA fragments (HindIII, SphI) that were smaller than the expected $\mathrm{S} \mu$ germline band, but hybridized with both the $5^{\prime}$ flanking and the $3^{\prime}$ flanking $S \mu$ probe, represent a $\Delta S \mu$. For LDPCR, three primer sets that span the region between the intronic enhancer $(\mathrm{E} \mu)$ and $\mathrm{C} \mu$ were used. $\Delta \mathrm{S} \mu$ were found in seven out of $16 \mathrm{BLs}$ (Table 3). The size of the deleted region ranged from 0.2 to $3 \mathrm{~kb}$. For all but one case (3815), Southern blotting and LD-PCR yielded similar results. Southern blotting identified two different $\Delta \mathrm{S} \mu(0.2$ and $1.8 \mathrm{~kb})$ in 3815 , whereas only the $1.8 \mathrm{~kb}$ deletion was found by LD-PCR. This could be due to deletion or mutation of (part of) one of the $\mathrm{S} \mu$ primer sites. Two different deletions were also identified in patient 5814; this could be caused by a biallelic event or the presence of two subclones with different deletion on one allele. The $\Delta S \mu$ did not correlate with a translocation in $\mathrm{S} \gamma$ or $\mathrm{S} \alpha$, making it unlikely that $\Delta S \mu$ is of importance for breakpoints involving downstream switch regions.

\section{DISCUSSION}

We have characterized the $t(8 ; 14)$ chromosomal translocation in 16 Burkitt lymphomas and show that cases with a $S \gamma$ or $S \alpha$ breakpoint have two unusual features. (1) No $\mathrm{S} \mu-\mathrm{S} \gamma / \mathrm{S} \alpha$ recombinations were present but only breakpoints directly involving the downstream switch regions. (2) Illegitimate switch region recombination was not accompanied by class switch recombination on the nontranslocated $I G H$ allele.

Normally, CSR is resolved by ligation of DNA double stranded breaks in $\mathrm{S} \mu$ and a downstream switch region, whereby the intervening DNA between $S \mu$ and the downstream switch region is excised and circularized (Fig. 4A). In case of a breakpoint involving a downstream switch region, this process would result in the juxtaposition of a putative oncogene to the downstream switch region at the der(14) chromosome and the juxtaposition of $\mathrm{S} \mu$ to the derivative chromosome that originally harbored the oncogene (Fig. 4B). However, while this configuration is encountered in mouse plasmacytomas and human myelomas, it was not observed in BL with $S \gamma$ or $S \alpha$ breakpoints, as those breakpoints exclusively involved the downstream switch region. Furthermore, secondary CSR events in which a switch breakpoint was followed by a $\mathrm{S} \mu-\mathrm{S} \gamma / \mathrm{S} \alpha$ recombination (Figs. 4C and 4D) were not found in
BL. Moreover, in most multiple myelomas and mouse plasmacytomas, both $I G H$ alleles have undergone CSR events, which is clearly not the case in BL. The perfect reciprocal nature of the switch breakpoints is not unique to $\mathrm{BL}$, but has been described also for other leukemias and lymphomas (Showe et al., 1985; Ohno et al., 1993; Muller et al., 1995; Chesi et al., 1997, 1998a,b; McKeithan et al., 1997; Schmidt et al., 2004). Importantly, however, we show that this switch breakpoint configuration is the only one encountered in BL.

We previously described abnormal downstream CSR events in follicular lymphoma. In these lymphomas, all cases with a downstream CSR events also had large internal $\mathrm{S} \mu$ deletions (Vaandrager et al., 1998), suggesting that internal $S \mu$ deletion is a primary event rendering $S \mu$ physically unavailable for normal CSR. In consequence, CSR could only start at downstream $\mathrm{S} \gamma$ or $\mathrm{S} \alpha$ sites. A similar hypothesis has been proposed for the role of $\Delta \mathrm{S} \mu$ in 'IgM-isotype stabilization' in normal mouse B cells (Zhang et al., 1995). Internal $\mathrm{S} \mu$ deletions, which are closely related to physiological CSR, are restricted to germinal center or post-germinal center B-cell derived malignancies like BL, follicular lymphoma, B-cell chronic lymphocytic leukemia (Nardini et al., 2002), and hairy cell leukemia (own unpublished observations), and are not found in lymphomas derived from pregerminal center B cells such as mantle cell lymphoma (data not shown). In this study, we show that not all BL cases with downstream switch breakpoints have a $\Delta \mathrm{S} \mu$, and opposite not all BL cases with $\Delta \mathrm{S} \mu$ show downstream switch breakpoints. Our observations, therefore, argue against a model in which the downstream switch translocations are just the favorable outcome of an erroneous CSR process wherein $S \mu$ cannot take part in the recombination process. This is in agreement with the results of a recent mouse gene-targeting study showing that deletion of $S \mu$ and large parts of its flanking sequences did impair but not completely abolish normal CSR (Khamlichi et al., 2004).

Germline transcription through unrearranged constant regions directs CSR. Although germline transcription from I $\mu$ through $S \mu$ is independent of cytokines, germline transcription of the individual$\gamma,-\alpha$, or $-\epsilon$ switch regions is directed by specific cytokines (Stavnezer-Nordgren and Sirlin, 1986; Coffman et al., 1993; Stavnezer, 1996). One could reason that defective/abnormal germline transcription is involved in misguided CSR and switch translocations. In this line of thinking, downstream switch breakpoints might result from improper activation or timing of germline transcription through 
A

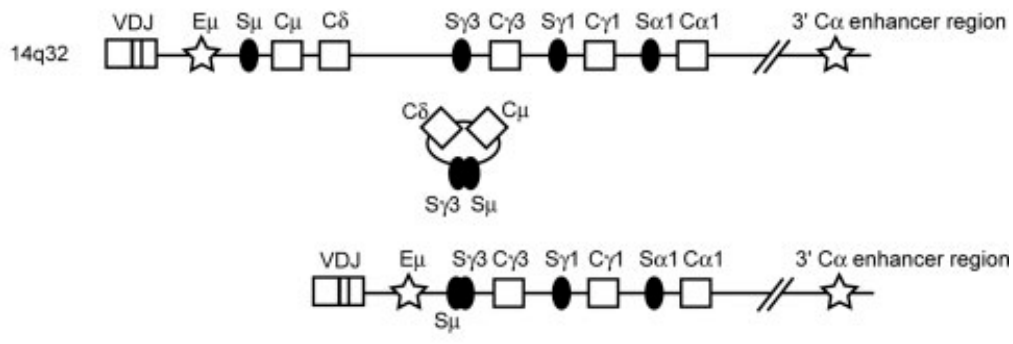

B der(14) translocation partner

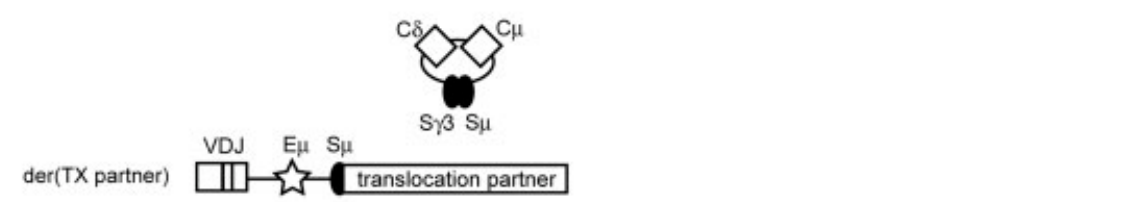

C

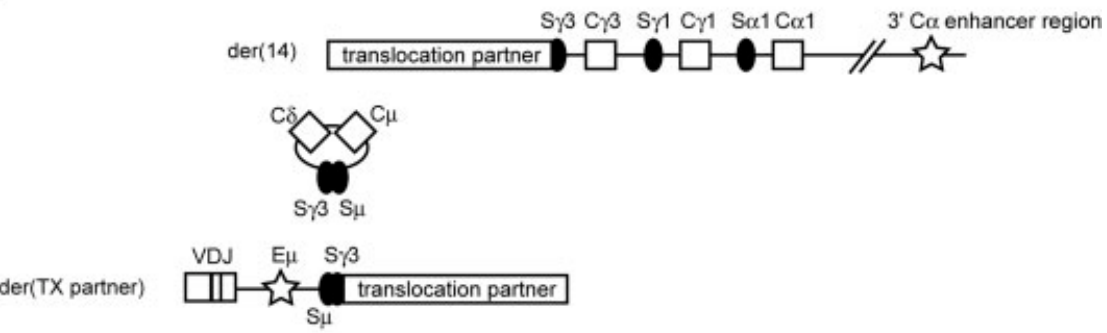

Figure 4. Schematic representation of CSR and different switch translocations. A: Legitimate $\mu-\gamma 3$ CSR. B: Typical switch translocation, the $\operatorname{der}(14)$ chromosome harbors a breakpoint in $S \gamma 3$, whereas $S \mu$ is linked to the derivative partner chromosome. Intervening DNA is looped out and excised as during normal CSR. C: Translocation involving a switch-switch junction that is linked to the derivative of the partner chromosome. Either the translocation was preceded by a legitimate switch $\mu$ $\gamma 3$ recombination, or the translocation event was followed by the switch recombination. D: Translocation involving a switch-switch junction that is linked to $\operatorname{der}(14)$. This particular structure suggests that the translocation event was preceded by a legitimate CSR. E: Example of a downstream switch translocation found in BL. S $\mu$ is not involved, no looping out and excision of DNA intervening $S \mu$ and a downstream switch region.

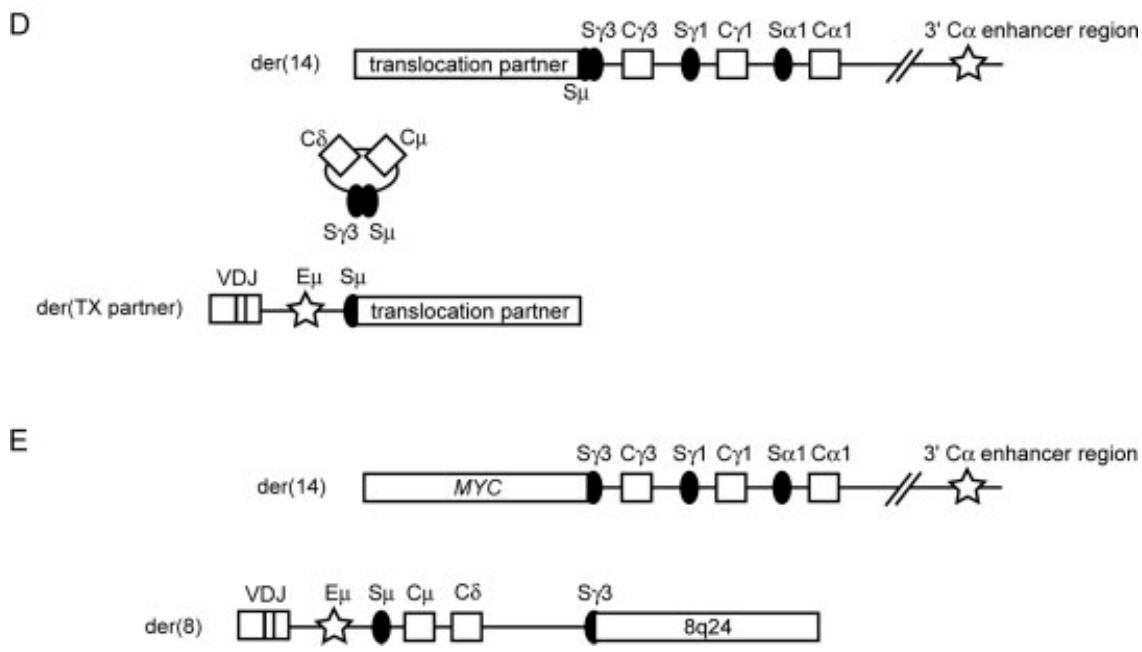

$\mathrm{C} \mu$ and the downstream constant region to which $M Y C$ is eventually juxtaposed. Nonsimultaneous activation/targeting of the switch regions would then result in a $\Delta \mathrm{S} \mu$ and a downstream switch breakpoint structure as observed in BL. BL cell lines such as Ramos, DG-75, and DND39 have low levels of baseline germline transcription of other isotypes than IgM, but germline transcription can be stimulated by cytokines (Ichiki et al., 1992, 1993; Ford et al., 1998; Ikizawa and Yanagihara, 2000; Basaki et al., 2002). Thus, although germline transcription can occur in $\mathrm{BL}$ under in vitro conditions, it is not 
known whether at the moment of the generation of the translocation, upstream and downstream germline transcription was properly executed. This question is also relevant, since BL generally express IgM and not $\operatorname{IgG}$ or $\operatorname{IgA}$, and our analysis showed a complete germline status of the $\mathrm{CH}$ region of the nontranslocated allele. Furthermore, in only two cases the results suggested a biallelic $\Delta \mathrm{S} \mu(5814,3815)$. This lack of any normal CSR might indicate that BL cells or its predecessors in which the translocation took place simply represent B cells that are not exposed to the appropriate microenvironment and extracellular signals necessary for CSR, whereas other intracellular signals that are independent of cytokines are present.

An important feature of SHM, CSR, and $\Delta S \mu$ is that they all depend on the expression and activity of the activation-induced cytidine deaminase (AID) protein (Muramatsu et al., 2000; Revy et al., 2000; Dudley et al., 2002). In a previous study, we determined AID expression in this group of BL patients and showed that AID is expressed in all cases, albeit at a heterogeneous level (Smit et al., 2003). No apparent correlation was found between the AID expression level and the position of the breakpoint in the $I G H$ locus or the presence of $\Delta S \mu$ (data not shown). However, also here it should be taken in to account that the breakpoint is initiated in a precursor cell, while we can study only the endstage tumor cells.

The role of AID in SHM and CSR has unequivocally been demonstrated. However, the involvement of AID in the generation of IGH/MYC translocation is still controversial; although AID in combination with down-regulation of TP53 certainly favors the occurrence of Myc- $\mathrm{IgH}$ recombinations in the mouse (Ramiro et al., 2006), other studies suggested that these translocations can also occur in an AID independent manner and might be favored by the intrinsic fragility of switch regions in B cells (Unniraman et al., 2004). Fragility of switch regions is enhanced by germline transcription and hyperacetylation of histones (Nambu et al., 2003), resulting in the formation of stable Rloops (Yu et al., 2003). These features are considered as crucial factors for CSR, and therefore, the intrinsic fragility of switch regions can be regarded as an important functional component of CSR. Since an interswitch recombination, the hallmark of bonafide AID mediated CSR, was absent in our cases, we cannot rule out that the breakpoints described in this study were independent of AID. Analysis of $\mathrm{t}(8 ; 14)$ breakpoint DNA sequences (few patients from this series and retrieved from the NCBI database; Wilda et al., 2004) showed the presence of somatic mutations adjacent to the breakpoint (data not shown), which are considered a hallmark feature of AID activity. Although this does not formally prove the involvement of AID in the generation of the translocation itself, it shows that the involved switch regions in BL were targeted by AID.

Finally, a functional consequence of downstream switch translocation is that the VDJ-C $\mu$ transcription that is present on $\operatorname{der}(8)$ is not structurally disrupted and therefore could still be responsible for IgM expression. Previously, we have demonstrated that this is actually the case for the IgM-expressing Z-138 cell line (Guikema et al., 2005). In this cell line, both $I G H$ alleles are involved in chromosomal translocations, and $\mathrm{IgM}$ transcripts are derived from one allele which harbors a $\mathrm{t}(8 ; 14)$ breakpoint involving a $\mathrm{S} \gamma$ region. In the present study, at least one patient (4847) showed this phenomenon as well.

\section{REFERENCES}

Basaki Y, Ikizawa K, Kajiwara K, Yanagihara Y. 2002. CD40-mediated tumor necrosis factor receptor-associated factor 3 signaling upregulates IL-4-induced germline C- $\epsilon$ transcription in a human B cell line. Arch Biochem Biophys 405:199-204.

Basso K, Frascella E, Zanesco L, Rosolen A. 1999. Improved longdistance polymerase chain reaction for the detection of $t(8 ; 14)$ (q24;q32) in Burkitt's lymphomas. Am J Pathol 155:1479-1485.

Bemark M, Neuberger MS. 2003. By-products of immunoglobulin somatic hypermutation. Genes Chromosomes Cancer 38:32-39.

Bergsagel PL, Kuehl WM. 2001. Chromosome translocations in multiple myeloma. Oncogene 20:5611-5622.

Chesi M, Bergsagel PL, Brents LA, Smith CM, Gerhard DS, Kuehl WM. 1996. Dysregulation of cyclin D1 by translocation into an $\mathrm{IgH} \gamma$ switch region in two multiple myeloma cell lines. Blood 88:28712878

Chesi M, Bergsagel PL, Shonukan OO, Martelli ML, Brents LA, Chen T, Schrock E, Ried T, Kuehl WM. 1998. Frequent dysregulation of the c-maf proto-oncogene at $16 \mathrm{q} 23$ by translocation to an Ig locus in multiple myeloma. Blood 91:4457-4463.

Chesi M, Nardini E, Brents LA, Schrock E, Ried T, Kuehl WM, Bergsagel PL. 1997. Frequent translocation $\mathrm{t}(4 ; 14)(\mathrm{p} 16.3 ; \mathrm{q} 32.3)$ in multiple myeloma is associated with increased expression and activating mutations of fibroblast growth factor receptor 3. Nat Genet 16:260-264.

Chesi M, Nardini E, Lim RSC, Smith KD, Kuehl WM, Bergsagel PL. 1998. The $t(4 ; 14)$ translocation in multiple myeloma dysregulates both FGFR3 and a novel gene, MMSET, resulting in IgH/ MMSET hybrid transcripts. Blood 92:3025-3034.

Coffman RL, Lebman DA, Rothman P. 1993. Mechanism and regulation of immunoglobulin isotype switching. Adv Immunol 54:229 270.

Dudley DD, Manis JP, Zarrin AA, Kaylor L, Tian M, Alt FW. 2002. Internal IgH class switch region deletions are position-independent and enhanced by AID expression. Proc Natl Acad Sci USA 99:9984-9989.

Fenton JA, Pratt G, Rawstron AC, Sibley K, Rothwell D, Yates Z, Dring A, Richards SJ, Ashcroft AJ, Davies FE, Owen RG, Child JA, Morgan GJ. 2003. Genomic characterization of the chromosoma breakpoints of $\mathrm{t}(4 ; 14)$ of multiple myeloma suggests more than one possible aetiological mechanism. Oncogene 22:1103-1113.

Ford GS, Yin CH, Barnhart B, Sztam K, Covey LR. 1998. CD40 ligand exerts differential effects on the expression of I $\gamma$ transcripts in subclones of an $\mathrm{IgM}^{+}$human B cell lymphoma. J Immunol 160: 595-605.

Gilles F, Goy A, Remache Y, Shue P, Zelenetz AD. 2000. MUC1 dysregulation as the consequence of a $\mathrm{t}(1 ; 14)(\mathrm{q} 21 ; \mathrm{q} 32)$ translocation in an extranodal lymphoma. Blood 95:2930-2936. 
Guikema JE, Fenton JA, de Boer C, Kleiverda K, Brink AA, Raap AK, Estrov Z, Schuuring E, Kluin PM. 2005. Complex biallelic IGH rearrangements in IgM-expressing Z-138 cell line: Involvement of downstream immunoglobulin class switch recombination. Genes Chromosomes Cancer 42:164-169.

Gutierrez MI, Bhatia K, Barriga F, Diez B, Muriel FS, Deandreas ML, Epelman S, Risueno C, Magrath IT. 1992. Molecular epidemiology of Burkitt-lymphoma from South-America-Differences in breakpoint location and Epstein-Barr-Virus association from tumors in other world regions. Blood 79:3261-3266.

Haralambieva E, Schuuring E, Rosati S, van Noesel C, Jansen P, Appel I, Guikema J, Wabinga H, Bleggi-Torres LF, Lam K, van den Berg E, Mellink C, Zelderen-Bhola S, Kluin P. 2004. Interphase fluorescence in situ hybridization for detection of $8 \mathrm{q} 24$ / MYC breakpoints on routine histologic sections: Validation in Burkitt lymphomas from three geographic regions. Genes Chromosomes Cancer 40:10-18.

Ichiki T, Takahashi W, Watanabe T. 1992. The effect of cytokines and mitogens on the induction of $\mathrm{C} \epsilon$ germline transcripts in a human Burkitt lymphoma B cell line. Int Immunol 4:747-754.

Ichiki T, Takahashi W, Watanabe T. 1993. Regulation of the expression of human $\mathrm{C} \epsilon$ germline transcript. Identification of a novel IL-4 responsive element. J Immunol 150:5408-5417.

Ikizawa K, Yanagihara Y. 2000. Possible involvement of Shc in IL-4induced germline $\epsilon$ transcription in a human B cell line. Biochem Biophys Res Commun 268:54-59.

Khamlichi AA, Glaudet F, Oruc Z, Denis V, Le Bert M, Cogne M. 2004. Immunoglobulin class-switch recombination in mice devoid of any $\mathrm{S} \mu$ tandem repeat. Blood 103:3828-3836.

Kuehl WM, Bergsagel PL. 2002. Multiple myeloma: Evolving genetic events and host interactions. Nat Rev Cancer 2:175-187.

Küppers R, Dalla-Favera R. 2001. Mechanisms of chromosomal translocations in B cell lymphomas. Oncogene 20:5580-5594.

Lenoir GM, Vuillaume M, Bonnardel C. 1985. The use of lymphomatous and lymphoblastoid cell lines in the study of Burkitt's lymphoma. IARC Sci Publ 60:309-318.

McKeithan TW, Takimoto GS, Ohno H, Bjorling VS, Morgan R, Hecht BK, Dube I, Sandberg AA, Rowley JD. 1997. BCL3 rearrangements and $\mathrm{t}(14 ; 19)$ in chronic lymphocytic leukemia and other B-cell malignancies: A molecular and cytogenetic study. Genes Chromosomes Cancer 20:64-72.

Muller JR, Janz S, Potter M. 1995. Differences between Burkitts lymphomas and mouse plasmacytomas in the immunoglobulin heavy-chain c-myc recombinations that occur in their chromosomal translocations. Cancer Res 55:5012-5018.

Muramatsu M, Kinoshita K, Fagarasan S, Yamada S, Shinkai Y, Honjo T. 2000. Class switch recombination and hypermutation require activation-induced cytidine deaminase (AID), a potential RNA editing enzyme. Cell 102:553-563.

Nambu Y, Sugai M, Gonda H, Lee CG, Katakai T, Agata Y, Yokota Y, Shimizu A. 2003. Transcription-coupled events associating with the immunoglobulin switch region chromatin. Science 302:2137-2140.

Nardini E, Aiello A, Giardini R, Colnaghi MI, Menard S, Balsari A. 2000. Detection of aberrant isotype switch recombination in lowgrade and high-grade gastric MALT lymphomas. Blood 95:10321038 .

Nardini E, Rizzi S, Capello D, Vitolo U, Gaidano G, Menard S, Balsari A. 2002. Most immunoglobulin heavy chain switch $\mu$ rearrangements in B-cell chronic lymphocytic leukemia are internal deletions. FEBS Lett 518:119-123.
Neri A, Barriga F, Knowles DM, Magrath IT, Dalla-Favera R. 1988. Different regions of the immunoglobulin heavy-chain locus are involved in chromosomal translocations in distinct pathogenetic forms of Burkitt-lymphoma. Proc Natl Acad Sci USA 85:27482752 .

Ohno H, Doi S, Yabumoto K, Fukuhara S, McKeithan TW. 1993. Molecular characterization of the $\mathrm{t}(14 ; 19)(\mathrm{q} 32 ; \mathrm{q} 13)$ translocation in chronic lymphocytic leukemia. Leukemia 7:2057-2063.

Pelicci PG, Knowles DM, Magrath IT, Dalla-Favera R. 1986. Chromosomal breakpoints and structural alterations of the c-myc locus differ in endemic and sporadic forms of Burkitt-lymphoma. Proc Natl Acad Sci USA 83:2984-2988.

Ramiro AR, Jankovic M, Callen E, Difilippantonio S, Chen HT, McBride KM, Eisenreich TR, Chen J, Dickins RA, Lowe SW, Nussenzweig A, Nussenzweig MC. 2006. Role of genomic instability and p53 in AID-induced c-myc-Igh translocations. Nature 440:105-109.

Revy P, Muto T, Levy Y, Geissman F, Plebani A, Sanal O, Catalan N, Forveille M, Dufourcq-Labelouse R, Gennery A, Tezcan I, Ersoy F, Kayserili H, Ugazio AG, Brousse N, Muramatsu M, Notarangelo LD, Kinoshita K, Honjo T, Fischer A, Durandy A. 2000. Activation-induced cytidine deaminase (AID) deficiency causes the autosomal recessive form of the hyper-IgM syndrome (HIGM2). Cell 102:565-575.

Schmidt HH, Dyomin VG, Palanisamy N, Itoyama T, Nanjangud G, Pirc-Danoewinata H, Haas OA, Chaganti RS. 2004. Deregulation of the carbohydrate (chondroitin 4) sulfotransferase 11 (CHST11) gene in a B-cell chronic lymphocytic leukemia with a $\mathrm{t}(12 ; 14)(\mathrm{q} 23 ; \mathrm{q} 32)$. Oncogene 23:6991-6996.

Showe LC, Ballantine M, Nishikura K, Erikson J, Kaji H, Croce CM. 1985. Cloning and sequencing of a c-myc oncogene in Burkitt's lymphoma cell line that is translocated to a germline $\alpha$ switch region. Mol Cell Biol 5:501-509.

Smit LA, Bende RJ, Aten J, Guikema JE, Aarts WM, van Noesel CJ. 2003. Expression of the activation-induced cytidine deaminase is confined to B-cell non-Hodgkin's lymphomas of germinal-center phenotype. Cancer Res 63:3894-3898.

Stavnezer J. 1996. Antibody class switching. Adv Immunol 61:79-146.

Stavnezer-Nordgren J, Sirlin S. 1986. Specificity of immunoglobulin heavy chain switch correlates with activity of germline heavy chain genes prior to switching. EMBO J 5:95-102.

Unniraman S, Zhou S, Schatz DG. 2004. Identification of an AID-independent pathway for chromosomal translocations between the Igh switch region and Myc. Nat Immunol 5:1117-1123.

Vaandrager JW, Schuuring E, Kluin-Nelemans HC, Dyer MJ, Raap AK, Kluin PM. 1998. DNA fiber fluorescence in situ hybridization analysis of immunoglobulin class switching in B-cell neoplasia: Aberran $\mathrm{C}-\mathrm{H}$ gene rearrangements in follicle center-cell lymphoma. Blood 92:2871-2878.

Wilda M, Busch K, Klose I, Keller T, Woessmann W, Kreuder J, Harbott J, Borkhardt A. 2004. Level of MYC overexpression in pediatric Burkitt's lymphoma is strongly dependent on genomic breakpoint location within the MYC locus. Genes Chromosomes Cancer 41:178-182.

Yu K, Chedin F, Hsieh CL, Wilson TE, Lieber MR. 2003. R-loops at immunoglobulin class switch regions in the chromosomes of stimulated B cells. Nat Immunol 4:442-451.

Zhang K, Cheah HK, Saxon A. 1995. Secondary deletional recombination of rearranged switch region in isotype-switched B cells. A mechanism for isotype stabilization. J Immunol 154:2237-2247. 